\title{
Aerodynamic CFD study of Wortmann FX66-S-196 Airfoil
}

\author{
Enkhdavaa Purevsuren ${ }^{1}$ \\ State key Laboratory for Alternate Electrical Power System \\ with Renewable Energy Source, \\ North China Electrical Power University \\ Beijing 102206, China
}

\begin{abstract}
The aim of this study is a model the correct mesh size and, determined the varying $\mathrm{y}^{+}$until further increases in the mesh yielded no difference accordingly the focusing on the effect of grid scheme and turbulence models on the CFD model of wind turbine airfoil. In the investigation choose finitevolume method that the wall $y+$ as defined in selecting the good grid scheme and corresponding the standard RANS CFD approach is using by fluent software.

Numerical computations are implemented for the RISO National Laboratory FX66S-196 Vi airfoil. The SA, SST k- $\omega$ and RNG k- $\varepsilon$ models are used to analyzed to flow field structure which is modelled in steady-state flow. The airfoil domain was analyzed at various angel of attack. Performance of the both turbulence models is compared with experimental data from TU Delft.
\end{abstract}

Keywords - Wind turbine airfoil, aerodynamics coefficient, mesh size, CFD analysis,

\section{INTRODUCTION}

A core component of the wind turbine used to capture wind energy, aerodynamics performance of the blade airfoil directly affects the efficiency of the wind turbine. Therefore, in this document contains how to study of aerodynamics performance of wind turbine blade airfoil. Airfoil for horizontal axis wind turbine is generally designed to be used at low attack angle, where the drag coefficient is usually much lower than the lift coefficient.

Currently, the three main methods are the researcher and manufacturing to model wind turbine aerodynamic characteristics: Blade Element Moment (BEM) method, Lift line/surface/panel method, Computational Fluid Dynamics (CFD) method. The Blade Element Moment (BEM) theory which was firstly reported by Glauert in 1948. The features of these methods are:

- The BEM theory calculated the blade is divided into several sections and each section sweeps an annular area when the rotor rotates.

- Lifting line/surface/panel methods and Computational Fluid Dynamics (CFD) methods are widely applied in airfoil aerodynamic analysis in complex flow domain.

All these numerical methods are employed in near wake and far wake analysis.

Especially, the RANS CFD approach has been generally used to model and analyze the aerodynamic behavior of wind turbines, the detailed flow field characteristics around a rotating/non-rotating wind turbine rotor and blade in many turbulent models, such as Spalart-Allmaras (S-A), standard k-epsilon $(k-\varepsilon)$, k-omega $(k-\omega)$, the two-equation ReNormalization Group (RNG) k- $\varepsilon$ and Shear Stress Transport

\author{
De $\operatorname{Tian}^{2}$ \\ State key Laboratory for Alternate Electrical Power System \\ with Renewable Energy Source, \\ North China Electrical Power University \\ Beijing 102206, China
}

(SST) $k-\omega$ model further the power performance can be obtained by the CFD 2D/3D approach [1-7].

Commonly users can choose between two standard approaches: the first is a called "high Re" boundary condition that assumes a logarithmic low-of the-wall for the walladjacent cells and the second is a "low Re" boundary condition which resolves the entire boundary-layer including the sublayer with a very fine mesh [8].

In this study presents a numerical investigation the wall $\mathrm{y}^{+}$as guidance of selecting the applicable to correct grid configuration and corresponding turbulence models are investigated for the FX66-S-196VI airfoil was designed by Prof F.X. Wortmann of the University of Stuttgart at low Reynolds number by ANSYS, a computer simulation package with Fluent solver. In the same respect, prediction of pressure coefficient at different angles of attack were taken domain of the airfoil to determine stall condition and determined the lift and drag force on the FX66-S-196 IV. In this analysis was calculated at Reynolds number is $\operatorname{Re}=1 \cdot 10^{6}$.

The FX66-S196-VI airfoil has been subject of several numerical analyses. The flowing literature review applies:

J.H.M. Gooden [9] performed on investigation to obtain the 2D aerodynamics characteristics of the FX66-S-196-VI airfoil using the measurement were supported by potentialflow calculation (with and without wall) using to twodimensional panel method. The investigation aim is determined the position of the laminar separation bubble and transition at Reynold number ranging from $0.5 \cdot 10^{6}$ to $2.0 \cdot 10^{6}$ at angle of attack between $-6^{\circ}$ and $+20^{\circ}$. The investigation made for resulting data have been compared with "Stutt garter Profilkatalog”.

Naujokaitis and Lasauskas [10] performed analysis of the free and disturbed laminar-turbulence transition of difference in aerodynamics behaviors two airfoils and it is computed at low Reynolds numbers. The theoretical calculation was using the three codes are Eppler systems, XFOIL and RFOIL. Specifics of this study [10] is used in a nonintegrated inviscid plus boundary layer method and an integrated zonal viscid/inviscid method. The analysis aim's which code prediction is suitable for analysis at low Reynolds number airfoil flow with transitional separation bubble. This study carried out to compare calculation were using the three codes result are:

- The XFOIL code calculated lift curves are about 2.5\% higher than lift than RFOIL, but measurement data is still higher both calculation codes from approximately $1.9 \%$ at angle of attack $0^{\circ}$ in a post stall region. 
- Until increasing the angle of attack $14^{\circ}$, XFOIL code over predicts and RFOIL code under predicts the experiment result.

Indeed, experiment result are small by approximately $0.4 \mathrm{C}_{\mathrm{L}}$ than RFOIL code and by approximately $0.5 \mathrm{C}_{\mathrm{L}}$ than XFOIL code. On the other hand, the FX66-S-196-VI airfoil does not work at low Reynolds number. And XFOIL and RFOIL codes can be calculate all aerodynamics behavior of airfoil at low Reynolds numbers.

Lahaska's and Naujokaitis [11] performed using the three codes, which is PROFIL05, XFOIL and RFOIL on the FX66S-196-VI [Althaus 1972, Gooden 1979], E603 [Eppler 2005, Althaus 1996] and AH82-150A [Althaus 1996] at Reynolds number $1 \cdot 10^{6}$. All these codes predict the region of low Reynolds number. Some conclusions indicated by the investigations are:

- At low Reynolds number $\mathrm{Re}=0.7 \div 1.0 \cdot 10^{6}$ Eppler's code predicts lift curve is about in the middle between XFOIL prediction and RFOIL prediction.

- At low Reynolds number Re $=0.7 \div 1.0 \cdot 10^{6}$ Eppler's code predicts lift curve is about in the middle between XFOIL prediction and RFOIL prediction.

- Eppler's code predicts drag in low drag region better than RFOIL and XFOIL code.

The study [11] is indicated for which simulation codes, it is possible to get effective result when using the conditions. Finally, compare calculation airfoil characteristics [Pakalnis et al 2005], obtained using mentioned code with published measurement data [9] of airfoil.

\section{METHOD OF NUMERIACAL APPROACH}

In this study, the establishment of calculation model and the set of meshing and boundary conditions are adopting pretreatment software ANSYS ICEM and FLUENT solver.

\section{A. Model descriptions}

The FX66-S196-VI profile has been specially designed for sailplane by Prof F.X. Wortmann of the University of Stuttgart [9] if it tick airfoil (19\% of thickness) it would be adapted low- Reynolds number of flow.

This airfoil several wind tunnel was tested by [Althaus 1972, Gooden 1979] and the coordinate of the FX66-S196VI airfoil are published [9], which has a the model has a chord length of $0.36 \mathrm{~m}$.

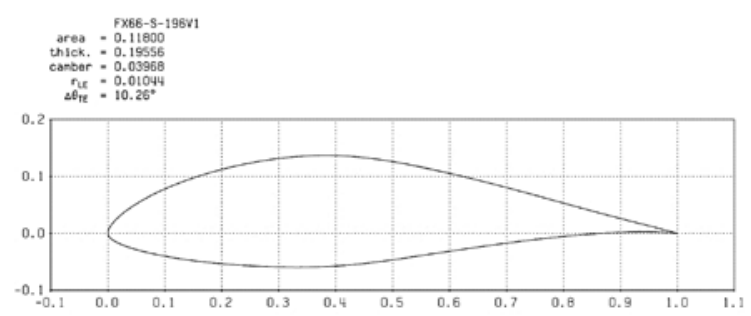

Fig. 1. Two-dimensional airfoil map of FX66-S-196VI [11]

The 2D airfoil modelling was performed to study the laminar-turbulence models and mesh grid test. The mesh quality, number of element and domain size of the CFD model do affect the computation accuracy and convergence time. A good mesh should be parallel with the streamlines of the flow and the domain size should be far enough to avoid boundary effects [12]. The many mesh topologies are modelling for airfoil CFD computation. The "O" mesh which is selected to provide a circular field surrounding an airfoil, is often used with a far-field pressure boundary condition and ideal gas. When the flow field is air, the most suitable mesh topology is the " $\mathrm{C}$ " and " $\mathrm{H}$ " mesh which is designed to have a C-type topology and H-type topology around the airfoil flow field. Considering the viscosity effects, the normal air (not ideal gas) is considered for wind turbine aerodynamics. The mesh used here is the H-topology structured mesh.

In this part of the several experimental tests [Althaus 1972 , Gooden 1979] is carried out on a $0.36 \mathrm{~m}$ chord. FX66$\mathrm{S}$-196VI airfoil $\mathrm{Re}=1.0 \cdot 10^{6}$ the flow parameter at the inlet are a velocity $\mathrm{V}=14.6 \mathrm{~m} / \mathrm{s}$ and turbulence intensity of $0.025 \%$. The mesh domain for the calculation, which is up, upper and bottom stream is were placed at the distance for 15 chords, while the downstream boundary is ware placed at the 20 chords as illustrated in Figure 3.

\section{B. Wall treatment and mesh size}

Near-wall regions have larger gradients in the solution variables, and momentum and other scalar transports occur most vigorously [3] and from Figure 3 it can be observed that the viscosity-affected region (the inner layer in this case) is made up of two zones with their corresponding wall $\mathrm{y}^{+}$.

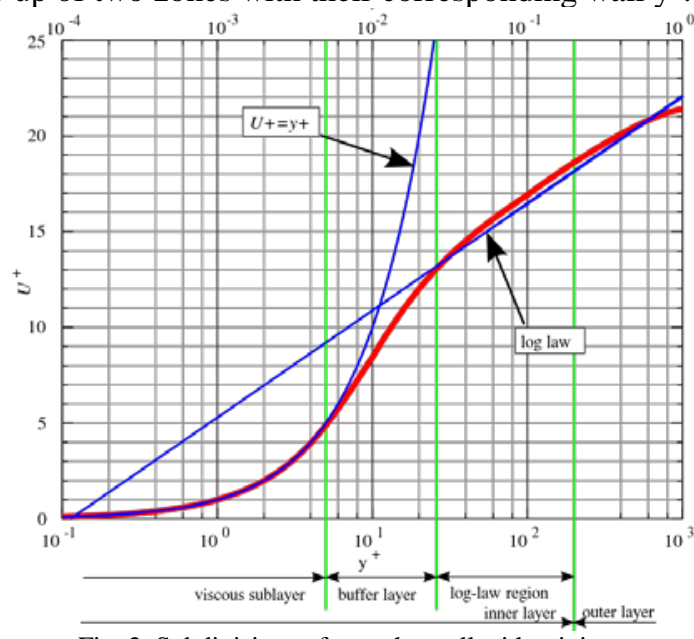

Fig. 2. Subdivisions of near the wall with mixing length model [Wall $\mathrm{y}^{+}$]

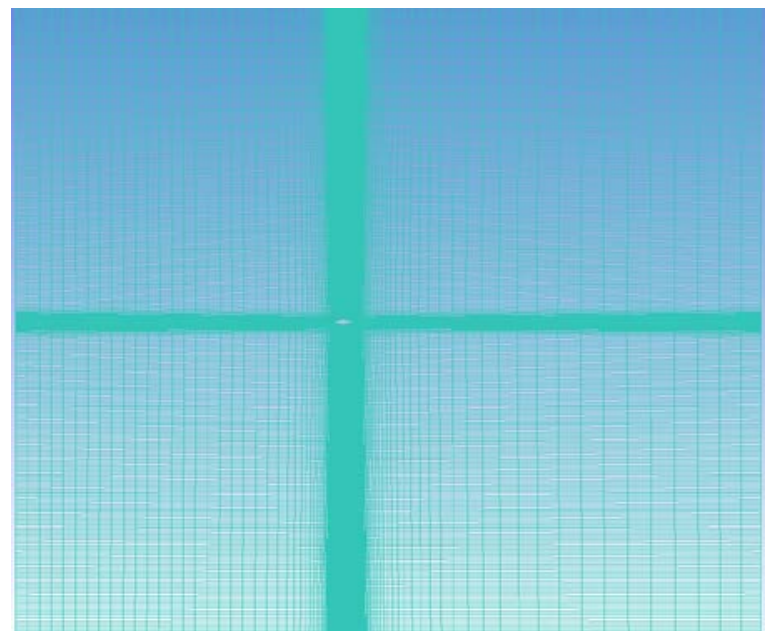

Fig. 3. The boundary figure far field and Computational flow domain topology 
The wall $\mathrm{y}^{+}$is a non-dimensional distance similar to local Reynolds number, often used in CFD to describe how coarse or fine a mesh is for a particular flow. It is described the ratio of between the turbulent and laminar effects in a cell. Kinematic blocking reduces the normal fluctuations of the cause by viscous damping to reducing the tangential velocity fluctuations in closer to the wall. Towards the outer part of the near-wall region, however, the turbulence is rapidly augmented by the production of turbulent kinetic energy due to the large gradients in mean velocity.

Accurate presentation of the flow in the near-wall region determines successful prediction of wall-bounded laminarturbulent flows. Values of $\mathrm{y}^{+} \approx 1$ are the most desirable for near-wall modeling [3].

To conduct the current computation, ANSYS FLUENT a flow solver was applied, while the meshing process was using the ICEM CFD. An initial grid with from 40446 to 109246 cells was generated and the nodes were place closer near the airfoil where the dimensionless wall unit $\mathrm{y}^{+} \leq 1$ was controlled at different mesh size show in Table 1.

TABLE I. THE SENSICTIVE OF THE MESH SIZE

\begin{tabular}{|c|c|c|c|c|}
\hline Case & Cells & $\begin{array}{c}\text { Minimum } \\
\text { Orthogonal Quality }\end{array}$ & $\begin{array}{c}\text { Maximum } \\
\text { Aspect Ratio }\end{array}$ & $\mathbf{y}+\mathbf{m a x}$ \\
\hline Case 1 & 40446 & $5.53186 \mathrm{e}-02$ & $4.52744 \mathrm{e}+03$ & 1 \\
\hline Case 2 & 57366 & $1.94453 \mathrm{e}-01$ & $7.83314 \mathrm{e}+02$ & 0.85 \\
\hline Case 3 & 83666 & $2.14655 \mathrm{e}-01$ & $9.02312 \mathrm{e}+02$ & 0.55 \\
\hline Case 4 & 104206 & $5.94752 \mathrm{e}-02$ & $4.52697 \mathrm{e}+03$ & 0.1 \\
\hline Case 5 & 109246 & $5.94752 \mathrm{e}-02$ & $4.52697 \mathrm{e}+03$ & 0.055 \\
\hline
\end{tabular}

We should to emphasize that the effect that a number of grid (number of cells) point is increased and varying $\mathrm{y}^{+}$until the error in the numerical solution would decrease which is the agreement with experiment value and numerical result.

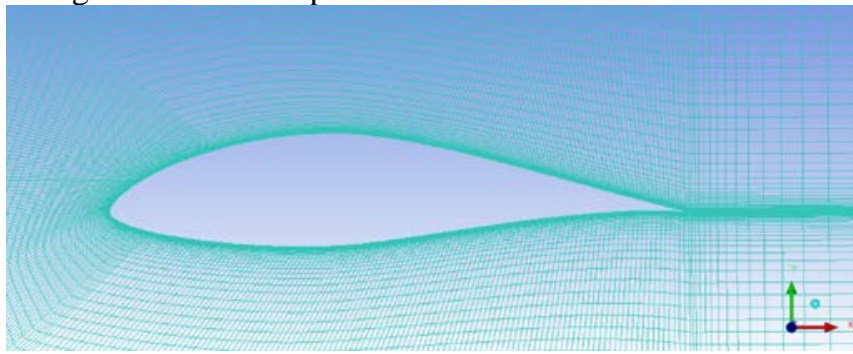

Fig. 4. Grid topology mesh for airfoil FX66-S-196VI

\section{Boundary condition}

The input parameters such as pressure, density and viscosity are considered at default conditions. The input velocity at the inlet is set for a chord-based Reynolds number at $\operatorname{Re}=1.0 \cdot 10^{6}$. The top and bottom walls of the rectangular domain are assigned as the inlet and the outlet is located behind the trailing edge of airfoil.

The turbulence intensity is set at $0.025 \%$ which is giving by the experimental report [9]. The flow is incompressible; hence a pressure-based solver is used. SIMPLE pressure velocity coupling is implemented. In order to avoid calculation errors, double precision is set. Second order discretization is set for pressure, momentum and other parameters. The angle of attack in the study by [9].

\section{Turbulence Modelling}

This study used fluent software is based on the theory of CFD which numerical calculation equations is are equal to the two-dimensional continuing equations, two-dimensional $\mathrm{N}-\mathrm{S}$ equations and energy equations.

The three models are compared for the closure of the time-averaged turbulent flow equations. The governing equations for the SST k- $\omega$, S-A and RNG k- $\varepsilon$ can be founded [3].

For mesh size, a balance is required between the desired calculation tolerance and the accepted computing time. 2D airfoil simulation with a 2D domain from 40446 to 109246 with a total number of cells for all the turbulence models including the all models. The parameters which are set in FLUENT are following Table 1.

TABLE II. THE PARAMETERS WHICH ARE SET IN FLUENT
\begin{tabular}{|l|c|}
\hline \multicolumn{1}{|c|}{ Solver } & Parameter based steady state \\
\hline Viscous model & SST k- $\omega$. S-A, RNG k- $\varepsilon$ \\
\hline Viscosity $(\mathrm{kg} / \mathrm{m}-\mathrm{s})$ & 1.7894 \\
\hline Density $\left(\mathrm{kg} / \mathrm{m}^{3}\right)$ & 1.255 \\
\hline Turbulent viscosity ratio & $0.025 \%$ \\
\hline Renoylds number & $1 \cdot 10^{6}$ \\
\hline Chord length & $1.0 \mathrm{~m}$ \\
\hline Momentum & Second order wind \\
\hline Pressure velosity coupling & SIMPLE \\
\hline
\end{tabular}

\section{THE RESULT AND ANALYSIS OF THE COMPUTATION}

The computation included flow investigation and determination of the basic, two-dimensional, low speed characteristic at Reynolds number at $1 \cdot 10^{6}$. special core was devoted to a correct mesh grid of the fluid domain.

The grid independence study was tested out cases, varying the number of cells in the central region as shown in Figure 5. This method increased the grid size and varying $\mathrm{y}^{+}$ that it was suitable for the different mesh size. It be noted that grid independence study was does not changing grid growth ratio were placed all domain. The grid convergence was according to Table 1 and varied considering Cases respectively in the fluid domain of the airfoil. This study was on simulation performed at an angle of attack of $12.985^{\circ}$ with the fine grid and with the lift and drag coefficient calculated to the different turbulence models.
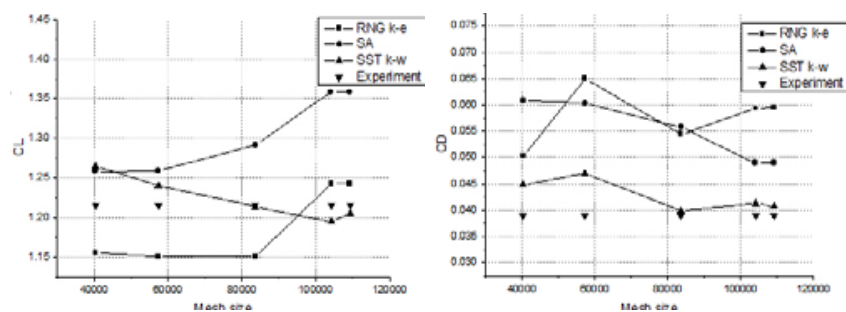

Fig. 5. Grid convergence

The aerodynamics coefficient calculated after the Case 5 was S-A and RNG k- $\varepsilon$ models no further variation of SST $k-\omega$ but mismatch experiment value. Consequences the $C_{L}$ and $C_{D}$ as 
set as the criterion for mesh dependency. Following the application of SST k- $\omega$ result obtained with the Case 5 mesh the simulation considering other turbulence models for the result was carried out.

As the main aim of study was to model the correct mesh scheme and the choice of suitable $\mathrm{y}^{+}$until further increases in the mesh yielded no difference in the aerodynamics coefficient values. For this purpose, in the initial 109246 cells grid was quite enough to prediction the results which is errors are minimal compared to others. Therefore, this Case 5 was selected for the numerical calculation on further analysis which is analysis of by plotting the contour plots (Figure 8 and 9) the flow physics differed.

Lift and drag forces are obtained from the computations by using the steady-state formulation with the SST k- $\omega$, S-A and RNG $\mathrm{k}-\varepsilon$ models for the $1.96^{\circ}$ to $20.01^{\circ}$ angel of attack range by integrating the pressure and shear stress over the airfoil surface in Case 5. The mesh configurations and corresponding wall $\mathrm{y}^{+}$have a significant influence on the comparisons between calculated and experimental aerodynamics coefficient results as show in Figure 6.

The predicted lift coefficients $\mathrm{C}_{\mathrm{L}}$ are in a good agreement with experimental data for from the $-6^{\circ}$ to $+6^{\circ}$ range if higher angle of attack range it predicted lower from experimental data. The predicted drag coefficients $C_{D}$ obtained with steady computations are illustrated on Figure 7. Highlight, the same as previously except that large values of $C_{L}$ is predicted around at $12.958^{\circ}$.

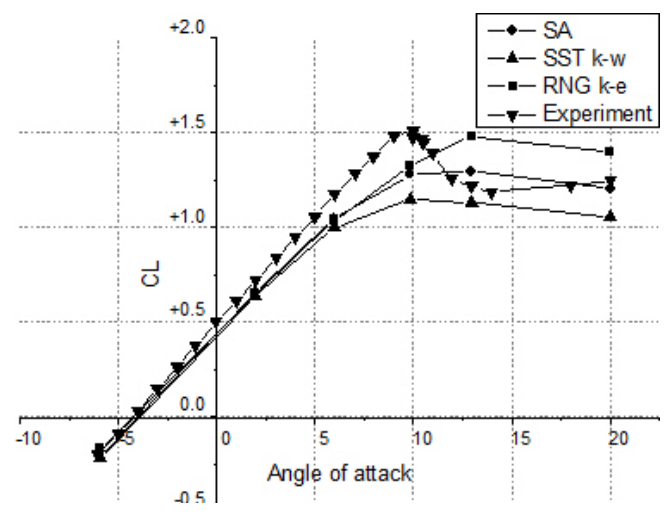

Fig. 6. The change of the Left coefficient of the up resistance with change of attack angle

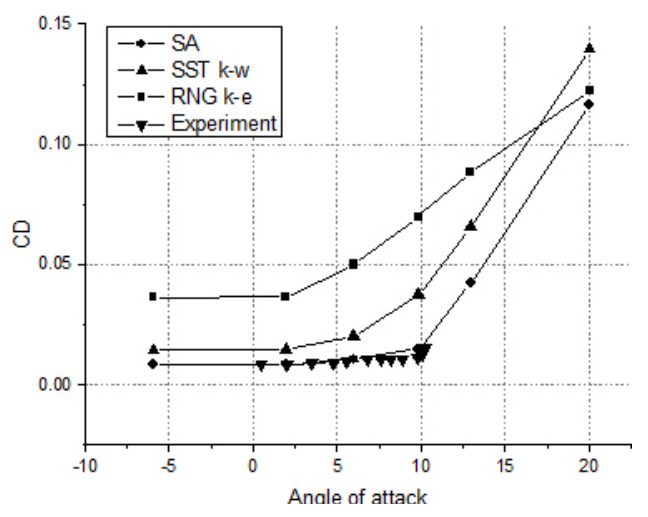

Fig. 7. The change of the Drag coefficient of the up resistance with change of attack angle

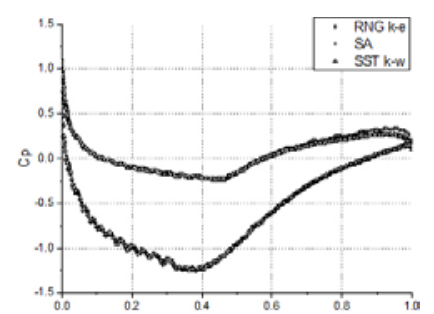

(a) $\alpha=1.96^{\circ}$

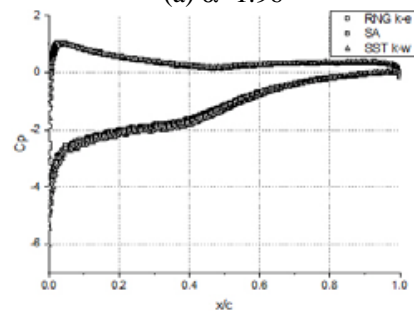

(c) $\alpha=12.98^{\circ}$

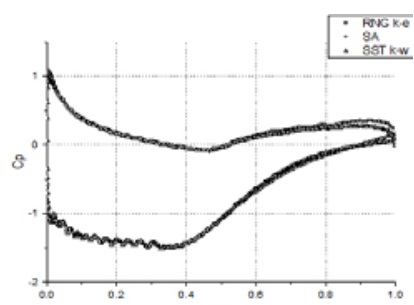

(b) $\alpha=5.98^{\circ}$

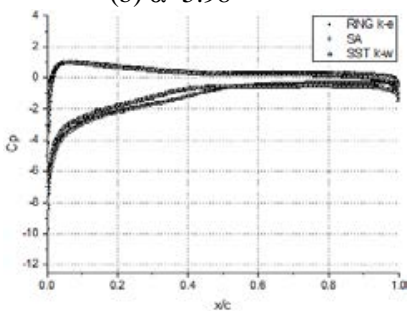

(d) $\alpha=20.01^{\circ}$
Fig. 8. Pressure coefficient at various angle of attack following application of various models

Pressure variations over the airfoil surface at the angles of attack $\alpha=1.96^{\circ}, 5.98^{\circ}, 12.96^{\circ}$ and $20.01^{\circ}$ are shown in Figure 8 . When the angle of attack is same time both models predicted similar results

The obtained contours of velocity magnitude are shown on Figure 8 for the angles of attack $\alpha=5.98^{\circ}, 12.96^{\circ}$ and $20.01^{\circ}$. With both models the flow velocity distribution was similar for same angle of attack.
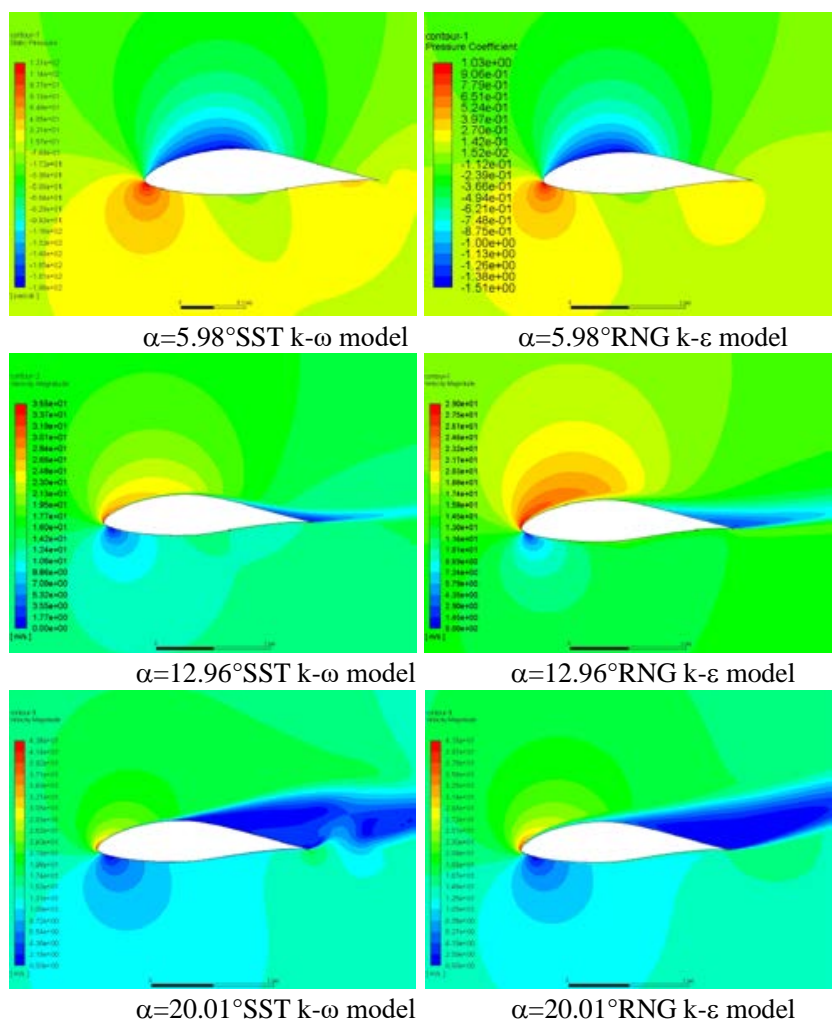

Fig. 9. Velocity distribution of airfoil fluid in different angle of attack 
Other hand begins to separate for $\alpha=12.96^{\circ}$ on the upper side appear at about $60 \%$ for the SST $\mathrm{k}-\omega$ model and at $50 \%$ for the RNG $k-\varepsilon$ model located from the leading edge. It means when the attack of angle is increases, to separation point movies to forward to leading edge.

\section{CONCLUSIONS}

This study has presented a numerical investigation introduces and the prediction of aerodynamics behavior of the two-dimensional flows over a wind turbine airfoil. The study was employed on the application of the commercial three turbulence models which is the SA model, SST k- $\omega$ model and RNG $\mathrm{k}-\varepsilon$ model are analyzed to flow field structure, were applied to predict flows over a FX66S-196 VI airfoil at Reynolds number at $1 \cdot 10^{6}$ and varying angles of attack. The all computation was based on commercial program ANSYS.

From these results, we concluded in the mesh size choice does not matter when the computing the velocity profile as observed. It means, if the $\mathrm{y}^{+}$is does not changing when the aerodynamic coefficient calculated after that the any models were applied no further variation. That's why that the mesh grid independence study was changing count of nodes and varying $\mathrm{y}^{+}$from 1 to 0.055 and does not changed grid growth ratio were placed between the airfoil and near-far field. It must be noted that this method gave us the sufficient results. In this study we chosen 109246 cells mesh with $\mathrm{y}^{+}=0.055$ the simulation considering three different turbulence models for the result was carried out.

The result obtained with all models are very similar over the $-6^{\circ}$ to $6^{\circ}$ range and gives the smallest lower prediction comparison with the experiment. The angle of attack $6^{\circ}$ to $12^{\circ}$ range all models are not similar with the experiment. Also angle of attack greater than $12^{\circ}$ only SA model very close to experiment. It can be explained that when the fluid domain boundary mesh resolution is sufficient, the SA model was describe to be applied throughout. The RNG k- $\varepsilon$ model gives the highest prediction of lift comparison with experiment value at around $12.958^{\circ}$ and at this time the separation point that is closest from this point.

\section{ACKNOWLEDGMENT}

The authors gratefully acknowledge the support of Laboratory of Alternate Electrical Power System and Renewable Energy Resource, North China Electrical Power University.

\section{REFERENCES}

[1] R. Yang and R.-N. Li, Research of the Rotational Effects on the Aerodynamics Characteristics of Horizontal Axis Wind Turbine, 2009.

[2] W. P. Wolfe and S. S. Ochs, CFD calculations of S809 aerodynamic characteristics, 1997.

[3] F. Villalpando, M. Reggio, and A. Ilinca, "Assessment of Turbulence Models for Flow Simulation around a Wind Turbine Airfoil," Modelling and Simulation in Engineering, vol. 2011, pp. 1-8, 2011.

[4] L. Lianbing, L. Lina, and M. Yuanwei, Numerical simulation on aerodynamic performance of wind turbine airfoil, 2012.

[5] D. Hartwanger and A. Horvat, 3D modelling of a wind turbine using CFD, 2008.

[6] R. K. Singh, M. R. Ahmed, and A. Zullah, Design of a Low Reynolds Number Airfoil for Small Horizontal Axis Wind Turbines vol. 42, 2012.

[7] M. Kevadiya, CFD Analysis of Pressure Coefficient for NACA 4412 vol. Volume 4, 2013.

[8] H. L. T. Rung, M. Schatz, M. Franke, "Universal wall boundary condition," 2009.

[9] J. H. M. Gooden, "External low-speed aerodynamic charakteristics the Wortmann FX66-S-196 VI airfoil," Department of Aerospace Engineering Deft University of Technology, The Netherlands, XVI OSTIV Congress Chatcauroux, France, 19781978.

[10] L. Naujokaitis and E. Lasauskas, "The Influence of Free and Disturbed Laminar-Turbulent Transition for the Wortmann Fx 66-S196 V1 and Eppler E 385 Airfoils at Low Reynolds Numbers," Mechanika, vol. 19, 2013.

[11] E. Lasauskas and L. Naujokaitis, "Analysis of three wing sections," Aviation, vol. 13, pp. 3-10, 2009.

[12] X. Tang, "Aerodynamic design and analysis of small horizontal axis wind turbine blades," School of Computing, Engineering and Physical Sciences, University of Central Lancashire, Preston, UK, September 2012. 